\title{
Management of IgG4-related sclerosing disease
}

\author{
Rushabh Doshi*, Mica Bergman and Jesse Berry \\ Ophthalmology, Keck School of Medicine, University of Southern California, Los Angeles, California, USA
}

\begin{abstract}
IgG4-related sclerosing disease is a systemic syndrome that is distinguished by high levels of both, IgG4 and IgG4-positive lymphoplasmocytic infiltrative lesions in the body. We report an occurrence of orbital IgG4-related disease in a 62-year-old Hispanic male. IgG4 related sclerosing disease involving the eyelids is a rare disease that affects patients ranged from ages 30 to 86 with a 1:1 male to female ratio. The patient presents a pseudotumor on his eyelids and the clinical presentation of this patient showed a bilateral eyelid nodular lesion. On the biopsy of orbital mass, there was an increase in IgG4 positive plasma cells, fibrosclerosis, and lymphoid hyperplasia. The patient was treated with an high dose of oral prednisone for a period of 3 months and was then placed on a maintenance dose. The work-up, diagnostic tools, and the final points in the treatment of this population are available and are discussed at length. It is important to note that IgG4 can affect the eyelids and physical findings, lab results, and biopsy results are required for correct diagnosis and treatment.
\end{abstract}

\section{Introduction}

IgG4-related disease(IgG4-RD)isasystemicsyndromecharacterized by the elevated levels of IgG4 and IgG4-positive lymphoplasmocytic infiltrative lesions in the body [1-5]. It is characterized by a tumor-like swelling of involved organs, a lymphoplasmocytic infiltrate enriched in IgG4-positive plasma cells, and a variable degree of fibrosis that has a "storiform", or a irregularly whirling pattern, of fibroblasts and inflammatory cells. IgG4 disease of the orbit can affect several ocular adnexal tissues including the lacrimal gland and the eyelids [6,7]. Manifestations of IgG4-RD of the orbit include inflammation, edema, and myositis [8]. Diagnosis of IgG4-related disease is made by both an elevated serum IgG4 and histopathological features including lymphocyte and IgG4 positive plasma cell infiltration [1,9]. The differential diagnosis for IgG4-related disease includes sarcoidosis, Castleman's disease, Wegener's granulomatosis, lymphoma, and cancer, so excluding these possibilities is important [10]. In this report, we present a case of IgG4-related disease of the orbit and discuss the work-up and management.

\section{Case report}

A 62 year old Hispanic male presented to our Ophthalmology Clinic with a six month history of a left-sided orbital mass that progressively increased in size, which was then complicated by a similar-appearing lesion on the right side. He endorsed minimally decreased vision on the left, but denied eye pain, diplopia, scotoma, or any other ophthalmic symptoms. He denied systemic symptoms including night sweats, weight loss, fever, or abdominal pain.

During physical examination, the patient was well-appearing with normal vital signs and a normal review of systems. External exam was significant for bilateral nontender, dense, lobular masses in the area of the lacrimal glands. A battery of laboratory tests including complete metabolic panel, complete blood count, lipid panel, erythrocyte sedimentation rate, $\mathrm{C}$ reactive protein, rheumatoid factor, thyroid stimulating hormone, lactate dehydrogenase, blood culture, and urinalysis were obtained, all of which were within normal limits. Excisional biopsy of the left orbital mass was performed and showed an increased IgG4-positive plasma cells, fibrosclerosis, and lymphoid hyperplasia, with no evidence of lymphoma. The IgG4 positive cells were kappa cells and lambda cells (polytype pattern) with $\mathrm{CD}^{+}$ and $\mathrm{CD} 45^{+} \mathrm{T}$ cells, CD20 ${ }^{+} \mathrm{B}$ cells, and $\mathrm{CD} 21^{+} \mathrm{CD} 138^{+}$follicular and interfollicular plasma cells.

Based on physical findings, lab results, and biopsy results, the patient was given a diagnosis of IgG4-related sclerosing disease with bilateral orbital involvement. He was started on $60 \mathrm{mg}$ of prednisone PO daily for four weeks. During this period, the patient showed a significant response, as evidenced by improvement in the nodular swelling of the eyelids. After four weeks, prednisone was tapered. After the taper, the nodular swelling continued to improve, resolving completely within 4 months. The patient was also referred to the oncology service, which ruled out lymphoma and other malignancy.

\section{Discussion}

Orbital IgG4-related disease classically presents with lid swelling and proptosis, and is often painless. Ocular motility may be restricted if there is enlargement of the extraocular muscles. There are generally no visual disturbances with these orbital lesions [11].

The lacrimal gland is the most commonly affected structure in orbital IgG4-related disease (69\%), and this may be unilateral or bilateral $[12,13]$. Patients with orbital IgG4-related disease may have other, non-orbital lesions, which are most frequently encountered in the submandibular glands (29\%), lymph nodes (14\%), pancreas (5\%), or bile ducts $(5 \%)[12,13]$. IgG4-related lesions in the thyroid and pituitary may also be present $[14,15]$. Patients with orbital IgG4-related disease often show bilateral involvement $(62 \%)[7,12,13]$.

The differential diagnosis for orbital IgG4-related disease is broad. Mimickers include marginal zone B-cell lymphoma, idiopathic orbital

Correspondence to: Rushabh Doshi, Ophthalmology, Keck School of Medicine, University of Southern California, Los Angeles, California, USA, E-mail: rushabh1999@gmail.com

Received: March 13, 2016; Accepted: March 25, 2016; Published: March 28 2016 
inflammation, idiopathic orbital myositis, antineutrophil cytoplasmic antibody (ANCA)-mediated systermic vasculitis (such as ChurgStrauss syndrome and granulomatosis with polyangiitis), and reactive lymphoid hyperplasia without IgG4-positive plasma cells [16].

Treatments for orbital IgG4-related disease may include systemic steroids, radiotherapy, or rituximab $[12,13]$. Oral glucocorticoids are typically first line treatment for IgG4-related disease. Improvement, and often resolution, of symptoms is typically seen with this therapy. With the discontinuation of steroids, however, relapse is common. As a result, chronic immunosuppression is often recommended, which may be with low dose prednisone, or with steroid-sparing agents such as azathioprine, mycophenolate mofetil, and methotrexate [1]. The efficacy of these drugs at preventing relapse is a topic for further investigation. In cases where prednisone is ineffective, Rituximab has also shown improvement both clinically and serologically [17], although recurrences have also been observed [13].

Given the success associated with treatment, early initiation is recommended. Further, prompt diagnosis and treatment is critical as, left untreated, patients with IgG4-related sclerosing may, in rare cases, develop malignancies including cholangiocarcinoma [18] and malignant lymphoma [19].

Cases of IgG4-related sclerosing may alternatively mimic malignancy, as has been seen in children with the Rosai-Dorfman disease (RDD), also known as sinus histiocytosis with massive lymphadenopathy [20]. Other cases have been reported as Idiopathic granulomatous Orchitis [21], which are Dura-based marginal zone lymphomas that represent an uncommon group of low-grade B-cell neoplasms [22]. Idiopathic cervical fibrosis, which has also been reported, is a rare tumefactive inflammatory-sclerosing lesion involving the soft tissues of the head and neck, and a proportion of patients also have synchronous or metachronous inflammatory fibrosclerosing lesions in other anatomic site and also reported IgG4-related chronic sclerosing sialadenitis of submandibular gland and lymphadenopathy seen. There is also supervening extranodal marginal zone lymphoma [23]. The adjacent lymph node from the same patient showed EpsteinBarr virus (EBV)-positive classical Hodgkin lymphoma with typical morphology and immunophenotype (CD30, CD15, PAX5). As a result, lymphoma is in correlation with chronic inflammatory background which is similar to that of the IgG4-related sclerosing disease of the ocular adnexa [23]. It is also reported as lung pseudotumor, the consolidations in the lung lobules such as the right $\mathrm{S}(2) \mathrm{b}$ and right $\mathrm{S}(3)$ were diagnosed as inflammatory pseudotumors with infiltrations of immunoglobulin G4-positive plasma cells [24].

\section{Conclusion}

In conclusion, we describe a rare case of IgG4 related sclerosing disease involving the eyelids. It is important to note that IgG4 can affect the eyelids. Physical findings, lab results, and biopsy results are required for correct diagnosis and treatment.

\section{References}

1. Stone JH1, Zen Y, Deshpande V (2012) IgG4-related disease. N Engl J Med 366: 539551. [Crossref]

2. Khosroshahi A, Stone JH (2011) A clinical overview of IgG4-related systemic disease. CurrOpinRheumatol23:57.

3. Smyrk TC (2011) Pathological features of IgG4-related sclerosing disease. Curr Opin Rheumatol 23: 74-79. [Crossref]

4. Umehara H, Okazaki K, Masaki Y, Kawano M, Yamamoto M, et al. (2012) A novel clinical entity, IgG4-related disease (IgG4RD): general concept and details. Mod
Rheumatol 22:1-14. [Crossref]

5. Smyrk TC1 (2011) Pathological features of IgG4-related sclerosing disease. Curr Opin Rheumatol 23: 74-79. [Crossref]

6. Takahira M, Kawano M, Zen Y, Minato H, Yamada K, et al. (2007) IgG4-Related Chronic SclerosingDacryoadenitis. Arch Ophthalmol 125: 1575-1578. [Crossref]

7. Sato Y, Ohshima K, Ichimura K, Sato M, Yamadori I, et al. (2008) Ocular adnexal IgG4-related disease has uniform clinicopathology. Pathol Int 58: 465-470. [Crossref]

8. Kitagawa S, Ooi A, Zen Y, et al. (2009) IgG4-related sclerosing diseases in head and neck. [Japanese]. Pathol Clinic Med 27: 35-41.

9. Hamano H, Kawa S, Horiuchi A, Unno H, Furuya N, et al. (2001) High serum IgG4 concentrations in patients with sclerosing pancreatitis. N Engl J Med 344: 732-738. [Crossref]

10. Masaki Y, Umehara H (2009) [IgG4-related disease-the diagnostic confusion and how to avoid it]. Nihon Rinsho Meneki Gakkai Kaishi 32: 478-483. [Crossref]

11. Kubota T, Moritani S (2012) Orbital IgG4-Related Disease: Clinical Features and Diagnosis.ISRN Rheumatol 2012: 412896. [Crossref]

12. Kubota T, Moritani S, Katayama M, Terasaki H (2010) Ocular adnexal IgG4-related lymphoplasmacytic infiltrative disorder. Arch Ophthalmol 128: 577-584. [Crossref]

13. Plaza JA, Garrity JA, Dogan A, Ananthamurthy A, Witzig TE, et al. (2011) "Orbital inflammationwith IgG4-positive plasma cells manifestation of IgG4 systematic disease". Arch Ophthalmol 129: 421-428. [Crossref]

14. JakobiecFA,StacyRC,HattonMP(2010)“Clinicalcharecterizationandimmunopathologic features of sclerosingdacryoadenitis and Riedel thyroiditis". Arch Ophthalmol 128: 1626-1628. [Crossref]

15. Patel SM, Szostek JH (2011) IgG4-related systemic disease in a Native American man. Intern Med 50: 931-934. [Crossref]

16. Cheuk W, Chan JK (2010) IgG4-related sclerosing disease: a critical appraisal of an evolving clinicopathologic entity. Adv Anat Pathol17:303. [Crossref]

17. Khosroshahi A, Bloch DB, Deshpande V, Stone JH (2010) "Rituximab therapy leads to rapid decline of serum IgG4 levels and prompt clinical improvement in Igg4 related systemic disease.Arthritis Rheum 62: 1755-1762. [Crossref]

18. Douhara A1, Mitoro A, Otani E, Furukawa M, Kaji K, et al. (2013) Cholangiocarcinoma developed in a patient with IgG4-related disease. World J Gastrointest Oncol 5: 181185. [Crossref]

19. Cheuk W, Chan JK (2010) IgG4-related sclerosing disease: a critical appraisal of an evolving clinicopathologic entity. Adv Anat Pathol 17: 303-332. [Crossref]

20. Zhao M, Li C, Zheng J, Yu J, Sha H, et al. (2013) Extranodal Rosai-Dorfman disease involving appendix and mesenteric nodes with a protracted course: report of a rare case lacking relationship to IgG4-related disease and review of the literature. Int J Clin Exp Pathol 6:2569-77. [Crossref]

21. Karram S, Kao CS, Osunkoya AO, Ulbright TM, Epstein JI (2014) Idiopathic granulomatous orchitis: morphology and evaluation of its relationship to IgG4 related disease. Hum Pathol 45: 844-850. [Crossref]

22. Venkataraman G, Rizzo KA, Chavez JJ, Streubel B, Raffeld M, et al. (2011) Marginal zone lymphomas involving meningeal dura: possible link to IgG4-related diseases. Mod Pathol 24: 355-366. [Crossref]

23. Cheuk W, Tam FK, Chan AN, Luk IS, Yuen AP, et al. (2010) Idiopathic cervical fibrosis-a new member of IgG4-related sclerosing diseases: report of 4 cases, 1 complicated by composite lymphoma. Am J Surg Pathol 34:1678-85.[Crossref]

24. Fujiu K, Sakuma H, Miyamoto H, Yamaguchi B (2010) Immunoglobulin G4-related inflammatory pseudotumor of the lung. Gen Thorac Cardiovasc Surg 58: 144-148. [Crossref]

Copyright: (C2016 Doshi R. This is an open-access article distributed under the terms of the Creative Commons Attribution License, which permits unrestricted use, distribution, and reproduction in any medium, provided the original author and source are credited. 